\title{
PODRIA DESCARTES EMBARCAR EN LA NAU DE NEURATH?
}

\author{
Josep L. Blasco \\ (Universitat de València)
}

La pregunta que intitula aquesta ponència pot semblar una mica exòtica i consequentment requerir algun aclariment. Aixi doncs, començaré aclarint el sentit de la pregunta i el tema que em propose dilucidar.

Potser podria haver estat més encertat plantejar ¿què queda de "l'epistemologia" cartesiana?, o més encara ¿pot afimar-se que Descartes inaugura l'epistemologia moderna? En qualsevol cas no vaig a plantejar un estudi sobre Descartes sinó una reflexió sobre els seus suggeriments epistemològics, des de la perspectiva de la teoria del coneixement actual. Tractaré doncs, de llegir Descartes en clau dels problemes epistemoldgics que avui ens plantegem. L'hermenèutica tradicional situa en Descartes l'inici del problema epistemològic, el punt d'inflexió de la pregunta pel ser a la pregunta pel conèixer. El meu propósit és reflexionar sobre aquest problema.

I per això la pregunta inicial. La imatge que pot reflectir l'estatus de l'epistemologia tal i com s'entén en un important corrent dels darrers anys la va formular en els anys 30 Otto Neurath, un filòsof del Cercle de Viena, en un conegut text que diu així:

No hi ha manera de prendre oracions protocolars concloentment establertes com a punt de pantença de les ciències. No hi la tabula rasa. Som com navegants que han de transformar llur nau en plena mas, sense mai no poder desguamir-la en dic per a carenar i reconstruir-la amb millors materials. Només els elements metafisics poden eliminar-se sense dejxar residus. D'una o altra manera sempre queden "conglomerats litgatstics" imprecisos com a components de la nau (O. Neurath "Proposicions protocolars", Ayer 206-207).

Aquesta coneguda metàfora de la nau vol dir que el coneixement cientific no té suports ferms, no pot nodrir-se de bases sòlides que li permeten navegar amb "seguretat", amb "certesa"; més aviat es tracta d'un constructe teòric que deu reparar els seus desperfectes en plena mar per tal d'evitar el naufragi: no hi ha protocols notarials de l'experiència que "donen fe" de les bases fonamentals del coneixement humà.

És cert que el pantejament cartesià del problema epistemològic "postula" certesa en el coneixement, perd pel moment, tot $\mathbf{i}$ que tornarem sobre el problema, Descartes no busca la certesa en els fonaments empirics, sinó en certes possibilitats de la raó d'intuir veritats indubitables. Aquest sistema epistèmic que explicita la fonamentació racional del coneixement Es anomenat per Descartes "prima philosophia". Aixi, el problema d'averiguar que queda de l'epistemologia cartesiana, o el que és el mateix: respondre la quilestió si Descartes pot embarcar en la nau, ve a complicar-lo Quine quan modifica la metàfora de Neurath afirmant que en la nau naveguen plegats el filòsof $i$ el cientific. Això diu un conegut text de Quine en el seu article "Gèneres naturals":

"Jo veig la filosolia no com una propedìutica a priori o tasca fonamentadora de la ciència. sinó com un continu anb la ciència. Veig la filosofia i la ciència en la mateixa nau —una nau que, per retornar a la imatge de Neurath com ho faig sovint, solament poden reparar en plena mar i llotant en ella - No li lua un punt avantatjós extem, no hi ha filosolia printera \{abans, en Parawla i Objecte havia dit "no hi ha exili còsmic"\}" (La Relat. Ont. (versió castellana) p. 162).

És conegut que aquesta tesi quineana va lligada al seu naturalisme, però no és aquest el motiu d'enfrontar-la a Descartes, sinó tan sols de prendre-la com a model d'una posició epis- 
temològica, avui generalment acceptada, que afirma que el coneixement, inclosa l'anàlisi filosòfica, no descansa en veritats fermes. Com ha recordat en els últims anys H. Putnam el que ja va proposar Kant: no hi ha un "ull divi", no hi ha un enteniment intuïtiu ( $\mathrm{i}$ no discursiu) que fonamente el coneixement.

Des d'aquesta doble perspectiva cal analitzar les aportacions cartesianes al problema del coneixement en un doble aspecte: l'aspecte de fonamentació empirica i l'aspecte de fonamentació intel-lectual o racional. Abans, però, d'aquesta anảlisi cal analitzar una quilestió prèvia: ¿pot afirmar-se que Descartes obri la teoria moderna del coneixement? Quine així ho afirma: "/'exigència cartesiana de certesa ha estat la motivació remota de l'epistemologia, en el seu doble aspecte conceptual i doctrinal. Tanmateix, aquesta exigència ha resultat una causa perduda" (Epist. Nat. p.75 (ed. orig.)). Intentaré provar que aquesta tesi segons la qual l'exigència cartesiana de certesa és l'origen de l'epistemologia és, si més no ingènua, no perquè Descartes no exigesca certesa, sinó perquè, al meu parer, és just aquest aspecte una herència del pensament diguem-ne pre-epistemologic (o si es vol, pre-modem).

Pense, i ho propose com a tema d'anàlisi, que el naixement de l'epistemologia, és a dir, la possibilitat d'una reflexió sistemàtica $i$ tot $i$ que imbricada en el complex de reflexions filosòfiques (lògiques, metafisiques...), autònoma i sense principis coactius externs a la pròpia reflexió, sols ha estat possible quan s'ha trencat un principi medieval ("verum et ens convertuntur) que pertany a lot l'esquema ideològic, filosòfic, politic... de l'ordre medieval: El veritable problema és si Descartes va trencar aquest principi. Vejam primer breument que implica aquest principi.

La identitat entre el ser i la veritat comporta una "misteriosa" proposició que he de confessar que sempre m'ha resultat dificil d'entendre: "l'ésser és vertader". Aristòtil ja va definir la veritat com una propietat (un predicat) dels enunciats (del “dir": dir de què és que és...); ¿què vol dir que "verum" siga un predicat de l'ens?: ho formularé amb una argumentació en llatí (treta d'un manual qualsevol, ja que totes són, pam dalt pam baix, iguals):

Tesi: Veritas ontologica non differt realiter ab entitate rei, quae dicitur vera.

- Prova: 1:Formalitas, per quam ens dicitur formaliter verum est ordo seu relatio ipsius entis ad aliquid.

2: Veritas dicitur formaliter de ente per ordinem ad intellectum.

3: Veritas dicitur de rebus per essentialem ordinem dependientae ad intellectum divinum.

4: Veritas dicitur de rebus etiam per ordinem ad intellectum creatum; at non per ordinem essentialem dependentiae, sed accidentalem et efficientae.

En l'argumentació s'utilitza la distinció entre la veritat per ordre essencial de dependència (intel-lecte divi) i per ordre accidental i d'eficiència (causa eficient) intel-lecte humà; aquest ordre accidental és possible perquè les coses (la veritat de rebus) són intel-ligibles, i aquesta intel-ligibilitat radica en la seua essencial dependència de l'intel-lecte divi: "ratio autem intelligibilitatis est ipsamet ratio veritatis".

Demane excuses per aquesta digressió medieval, però considere essencial, per tal d'entendre el problema epistemologic en Descartes, aquest corolari de l'argument: "la raó de la intel-legibilitat és ella mateixa la raó de la veritat" i la raó de la intel-legibilitat és Déu (l'essencial dependència de l'intel-lecte divi). Aquest és el sentit de la tesi medieval de la identitat ens-verum. 
Doncs bé, com he dit abans, l'epistemologia moderna, és a dir, l'epistemologia com a camp autònom de reflexió que té per objecte l'anàlisi dels processos cognitius, de llur estructura lógica $i$ dels limits $i$ abast del coneixement humd, sols pot constituir-se en la mesura que s'abandona (o es trenca) la identitat ens-verum. Aquest trencament com tota obra de la raó humana, no és cataclismàtic, sinó fruit d'un procès. ¿Quin és el paper de Descartes en aquest procès? No cap dubte que les reflexions cartesianes sobre el mètode, sobre l'activitat cognitiva lumana, sobre l'autoconciència (el cogito), sobre el coneixment matemàtic, sobre la física... (i si es vol, sobre la inutilitat de la lògica heretada), totes, totes van en la línia de mostrar la insatisfacció de l'ordre ontologico-epistèmic medieval. Descartes sap que aquesta tesi (ensverum) no funciona, perquè si fos correcta el Vaticà tindria raó en la condemna de Galileu i la ciència moderna no tindria raó de ser: la tesi de la veritat ontològica (ratio intelligibilitatis est ratio veritatis) implica que l'única "ciència" possible és la "ciència" subordinada a la teologia.

El pensament cartesià és una expressió viva, i m’atreviria a dir que dramàtica que aquest "ordo cognitionis" no funciona, no permet que el coneixement (humà) avance. Les tesis científiques que estan en questió (l'heliocentrisme, l'astronomia i la mecànica de Galileu...) no poden fonamentor-se en la veritat ontologica, queden des d'aquesta perspectiva sense fonament. Descartes, conscient d'aquesta escisió, ha obert la reflexió epistemológica moderna com una tensió entre teologia i epistemologia, entre el fonament divi de la veritat (l'ordre essencial) i el fonament humà (l'ordre accidental): el drama cartesid consisteix a adonar-se'n que l'epistemologia neix contra la teologia $i$ en pretendre vanament fer-les compatibles.

És per això que hom constata dos mons epistemològics en Descartes: el món de la fonamentació metafisica, la filosofia primera, i el món de l'experiència. En definitiva, en aquest plantejament cartesià s'inaugurarà una tensió inestable que recorrerà tota la filosofia moderna fins els nostres dies: la tensió entre raó i experiència, allò que Demissoff considera un problema impossible de resoldre: la paradoxa entre el mètode deductiu i l'observació empírica.

Des d'aquesta dualitat de mons epistèmics l'exigència de certesa està clarament formulada en Descartes en l'àmbit de la filosofia primera on el problema radica en superar l'escepticisme, demostrant que hi ha alguna veritat indubitable $i$ que Déu és garant tant de la capacitat de veritat de la raó humana com de la veritat dels enunciats que es refereixen al món extem. Però no sols es tracta de superar l'escepticisme, hi ha una altra qülestió que està present en aquest camp de problemes: la naturalesa del coneixement matemàtic. En la Regla XII, Descartes formula, tot $\mathrm{i}$ que d'una manera encara boirosa l'analiticitat en el coneixement matemàtic: “...puc conèixer el triangle, encara que mai haja pensat que en aquest coneixement està contingut també el coneixement de l'angle, de la línia, del número tres, de la figura, de l'extensió...; i això no impedeix, tanmateix, que digam que la naturalesa del tringle està composada de totes aquestes naturaleses, i que aquestes són més conegudes que el triangle, ja que aquestes mateixes són les que es comprenen en ell; $i$ en ell, a més a més, estan implicades altres moltes que se'ns amaguen, com la magnitud dels angles, que són iguals a dos rectes, $i$ innombrables relacions que lij ha entre els costats $\mathrm{i}$ els angles, o la capacitat de l'àrea, etc..." (p.128 ed, cast.).

Evidentment, si ens atenem a aquest text Descartes hauria proposat l'analiticitat del coneixement matemàtic, $\mathbf{i}$ per tant la seua fonamentació en els propis continguts conceptuals: del concepte de triangle se'n deriven un munt de conceptes; podriem aixi concloure que el coneixement geomètric rau en l'anàlisi dels conceptes.

Tanmateix, el problema no és tan senzill: l'analiticitat es fonamenta en la predicació nacessària $i$ sols requereix conceptes $i$ judicis basats en els propis conceptes. Descartes, però, fa raure la necessitat malemàtica en Déu. Un text de les respostes a Marsenne (segons objec- 
cions, Medit. Metaf., p.115-116, ed. cast.) diu: "no negue que un ateu puga coneixer amb claredat que els angles d'un triangle valen dos rectes; sols sostinc que no ho coneix mitjançant una ciència vertadera i certa, ja que cap coneixement que puga d'alguna manera posar-se en dubte pot ésser anomenat ciència; i ja que es tracta d'un ateu no pot estar segur de no enganyar-se en allò que li semble evidentíssim...". Una vegada més el coneixement cert té com a fonament a Déu. La raó metodològica d'aquesta exigència respecte de la matemàtica radica en què la deducció és en Descartes una cadena d'intuĩcions ("la deducció d'una cosa a partir d'altra es fa per intuïció" (R.XI)), i en la RIll diu: "aquesta evidència i certesa de la intü̈ció es requereix no solament per als enunciats sinó també per a qualsevol raonament. Aixi, per exemple, donada aquesta conseqüència: dos $i$ dos fan el mateix que tres $i$ un, no sols cal intuir que dos $i$ dos fan quatre, i que tres i un fan també quatre, sinó, a més a més, que d'aquestes dues proposicions se segueix necessàriament aquella tercera".

D’aquests textos se'n deriva que la deducció matemàtica no és algorímica, sinó fonamentada en la intuïció que copsa la necessitat de doctrina, $i$ en conseqüència rau en la fiabilitat de la capacitat intuitiva de la rá humana. Aquesta fiabilitat sols la garanteix Déu, que com a fonament de la intel-legibilitat és fonament de la veritat.

¿Podria pensar-se que Descartes deixa el cami obert a la tesi kantiana de la sintesi a priori que obri el constructivisme matemàtic actual? (No sóc propens a opcions hermenèutiques tan agosarades).

Cal dir, en honor a Descartes, que el problema del fonament de la veritat matemàtica que ell, com acabem de veure, ha plantejat ja en termes que avui diriem d'epistemologia moderna, no sols segueix sense resoldre, sinó que segueix vigent el seu plantejament: un conegut matemàtic alemany del segle xix, mestre de Cantor, (Kröneker) fonamenta en Déu els números naturals, i el platonisme d'alguns importants matemàtics del nostre segle (Frege, Gơdel) implica un recurs a estructures necessàries per sobre de la raó humana. Descartes digué que l'ateu no pot fonamentar la matemàtica com a ciència certa $i$ alguns filòsofs de la matemàtica del nostre segle segueixen apel-lant a entitats significatives universals, essencials (diu Russell): La diferència no és més que el procès modern de laicitzar la raó.

Recapitulem el que hem dit fins ara: he defensat que Descartes no ha trencat el binomi ens/ycrum, $\mathrm{i}$ que, en conseqüència l'exigència de certesa radica en Déu com a fonament de veritat. Però, pel que portem dit, Descartes ha obert dos problemes importants que inauguren la filosofia moderna: per una banda la recerca d'un criteri de certesa que tot i descansar en Déu li permeta fonamentar la ciència modema (tornaré sobre el tema) i per l'altra, plantejar de bell nou un problema fonamental de la modernitat, l'epistemologia de la matemàtica: Descartes la planteja com un joc entre intuïció i deducció, i m'atrevesc a afirmar, amb totes les cauteles que vulgam, que avui el problema segueix, en el fons, plantejat en els mateixos termes: la matemàtica és un joc entre creativitat (llibertat?) i necessitat (deducció).

És cert que en Descartes la raó és la clau de tota actitud intel-lectual i cientifica, però tinc dubtes, per tot el que he dit, que la raó haja assolit plena autonomia (això vol dir, que la raó es done les seues própies normes) en el pensament cartesià. Aquesta autonomia necessitarà de Hume i de Kant per fer passes importants en aquesta línia. Tanmateix calen algunes matisacions per a situar en el seu lloc la rá cartesiana: hi ha un problema dificil de resoldre dins de la coherència interna del sistema cartesià que se'n deriva de la tesi que planteja Descartes en les respostes a les segons objeccions on formula un conjunt "d'axiomes o nocions comunes" que són principis formals del tipus: no hi ha cap cosa existent de la qual no es puga indagar la causa de la seua existència, fins $i$ tot el mateix Déu, $i$ així fins a $X$ axiomes. Per a Descartes "estaria 
fora de tota rá posar en dubte en virtut d'algun prejudici dels sentits o d'alguna suposició capritxosa... el que l'enteniment concep amb claredat i distinció" ( 1 fed. p.132), es refereix als axiomes o nocions comunes. Així aquestes serien normes autònomes de la raó, i si aquesta interpretació és correcta implicaria que la raó mateira queda fora del dubte. Les consequències d'aquesta interpretació serien massa llargues per a tractar-les ara. En qualsevol cas, aquests dubtes hermeneutics estan en relació directa amb una altra tesi generalment atribuïda a Descartes: hom pot concloure del conèixer a l'ésser (a nosse ad esse valet consequentia). Aquesta hermenèutica implicaria que tot i no qüestionar-se la tesi de la veritat ontológica, el verum, els axiomes o nocions comunes de la raó comencen a obrir-se pas entre epistemologia i ontologia: el gir copemicà serà obra de Kant ( $i$ ho dic en sentit estricte: "assagem que siga l'enteniment qui determine l'objecte"), però Descartes posa pals a les rodes de l'ordre ontològic heretat.

Tornem al problema inicial: ¿el Descartes teòric de la raó pot navegar en la nau de Neurath? Pense que en la nau comandada per Quine, no. ¿Per què?, perquè la raó reguladora de l'epistemologia tal $\mathrm{i}$ com la concep Descartes, siga fonamentada en la intel.ligibilitat radicada en Déu, siga ja en l'inici del cami cap a la seua autonomia, no claudica en la seua funcio normativa (o reguladora) de les seues pròpies funcions cognitives. Aquesta raó no pot embarcar en la nau perquè si naufraga, naufraguem tots: la ciència, la societat, l’ètica... i per supost la raó mateixa. Però la pregunta seria ¿quina raó epistèmica pot embarcar? Pense que ni la raó quineana en la seua totalitat: podran embarcar les anàlisis de processos psico-fisiologics cognitius, però no mai l'epistemologia com a establiment de criteris epistemológics, ja que aquestes normes impliquen un distanciament de l'activitat cognitiva per tal de regular-la (fixar abast i valor) des de fora (des de fora de la nau). Permeteu-me una imatge: la pretensió de Quine d'embarcar en la nau l'ha de formular des de fora, des de la seua reflexió sobre el coneixement cientific, $i$ els navegants han de decidir que tinga el privilegi d'entrar $i$ eixir de la nau: d'embarcar per veure com van les coses $\mathrm{i}$ sobrevolar la nau per veure-la navegar des de fora, des de dalt. És això filosofía primera?

Fins aquí hem vist la tasca cartesiana de la fonamentació (epistemologia fonamentalista) racional del coneixement. Dedicaré els breus minuts que resten al problema de la fonamentació empirica. Recordem, per començar el famós text en el qual Descartes renega dels "filósofs que descuidant les experiències pensen que la veritat eixirà del seu propi cervell com Minerva del de Júpiter" (Regla V). Amb aquesta imatge, Descartes pretén poetular que les idees complexes s'lan de reduir a d'altres mis simples, $\mathrm{i}$ des d'aquestes, hom pot ascendir al coneixement de totes les altres (aquesta és la formulació de la $R$. V); $j$ en els comentaris critica els astròlegs que no observen el cel $\mathbf{i}$ els que pretenen una mecànica sense fisica. En aquesta regla es planteja el problema de l'experiència. El primer que vull fer notar és que si entenem per empirisme l'origen sensorial dels nostres conceptes (la tesi humeana del principi de còpia). l'epistemologia cartesiana estả ben lluny de l'empirisme, al menys pel que fa a les nocions abstractes, comunes o generals que són les rellevants per al coneixement. Caldria recordar a aquest respecte la crítica de Kant, al meu parer correcta, a la distinció racionalista (i cartesiana) entre coneixement sensible $\mathrm{i}$ intel-lectual com fosc $\mathrm{i}$ confús el primer, $\mathrm{i}$ clar $\mathrm{i}$ distint el segon; per a Kant, com és sabut, aquesta caracterització es refereix a l'estructura (i valor) lògica dels coneixements i no al seu origen. És conegut que en la meditació VI (p.64), Descartes rebutja el clàssic principi empirista "nihil est in intellectu quod prius non fuerit in sensu"; la raó d"aquest rebuig és l'engany dels sentits, engany del qual tenim "experiencia" ("diverses experiencies han anat demolint el crèdit que havia atorgat als meus sentits" (Med.VII. p.61). Lluny d'interpretar aquestes constatacions com que l'experiència sensorial es corregeiex a ella mateixa, Des- 
cartes opta pel descrèdit dels sentits: l'anomenat avui "argument de la il-lusió" porta Descartes no a establir les condicions d'ús de les proposicions perceptives, sinó l'atribució de confusió al coneixement sensible. És cert que admet les idees adquirides (les que provenen d'estimulacions externes), però aquestes no fonamenten coneixement. El fonamentalisme empirista, que és l'objecte de crítica de la nau de Neurath no cap en Descartes, més encara, Descartes recorre a raons pragmàtiques, com també farà Quine, per a l'acceptació de prosicions que fins i tot poden ser errònies, a aquest respecte és ben bonic i actual el paràgraf final de les Meditacions: "tanmateix, com la necessitat d'obrar amb urgència ens obliga sovint a decidir-nos sense haver disposat de temps per a exàmens acurats, cal reconèixer que la vida humana està subjecta a l'error en les coses particulars; cal, al capdavall, reconèixer la feblesa de la nostra natura". Evidentment, aquesta actitud cartesiana, ancorada en el pragmatisme, encaixa més amb la imatge d'un vaixell sense bases fermes, que amb l'arbre cartesià del saber.

Resta una altra qüestió en aquest repàs de l'epistemologia cartesiana, a la qual sols podré dedicar breus consideracions. Es tracta, no de l'empirisme, sinó del valor de l'experiéncia o millor, dels experiments en la metodologia científica. S'ha dit (Desmond Clarke, per exemple) que Descartes formula ja el mètode hipotètico-deductiu reclament els experiments per a validar les hipòtesis. No cal ser massa generós per a admetre que aquest esperit cientific ès una gran aportació de Descartes a l'epistemologia de la modernitat, per supost en sintonia amb el moviment cientific de l'època. Quan en el Discurs parla del fet que els principis són tan simples i tan generals que els efectes poden produir-se des d'aquells principis de molt diverses maneres (és a dir, poden establir-se diverses hipòtesis) i que "la meua major dificultat consisteix a trobar en quina d'aquestes maneres depén (l'efecte) d'ells (dels principis)" està formulant el problema de l'elecció entre diverses hipótesis i segueix:"...no conec altre expedient que cercar de bell nou algunes experiències tals que el seu esdeveniment no siga el mateix si cal explicarlo d'una d'aquestes maneres que si cal explicar-lo d'una altra" (Discurs, Vla Part)

Evidentment, aquests textos cartesians impliquen que ni cl mètode categòric-deductiu, model de raonament lògic, ni el mètode inductiu-deductiu (model metafisic) són suficients per a decisió científica. Descartes poatula la contrastació d'hipòtesis. El text anterioment citat ha estat interpretat com una postulació d'experiments crucials, $i$ això planteja un problema hermenèutic: faria fonamentalista l'epistemologia cartesiana, l'exigència d'expcriments crucials? Pense que els experiments crucials són un desideratum de l'activitat cientifica, s'han intentat $i$ s'intenten, una altra cosa és que puga convertir-se en norma epistemoldgica. Avui sabem que no, i a l'epistemologia correspon explicar les raons d'aquesta dificultat.

Que Descartes postulara experiments crucials en la seua metodologia cientifica posa de relleu que Descartes era conscient que la ciència s'ha de construir des de l'experiència. Si són possibles o no els experiments crucials i per quina raó, és encara una qüestió oberta en la metodologia cientifica. Crec, per completar el panorama epistemològic, que la distinció entre una fisíca general (metafisica) i una fisica aplicada (hipotètico-deductiva), distinció que arriba a Kant ( $i$ pense, tot $i$ que no és possible desenvolupar-ho, que fins als nostres dies) en Descartes suposa una dualitat de mons epistèmics: una fisica derivada $i$ fonamentada en Déu $i$ les "Ilavors de veritat", $\mathrm{i}$ una fisica basada en hipòtesis contrastables, que no ha de contradir la primera, però que no se'n deriva d'ella. És la manifestació palesa de la tensió moderna entre raó i experiència.

Per acabar. La metàfora cartesiana, a la qual m'he referit abans, de l'arbre, sembla l'antitesi de la metàfora de la nau. Diu Descartes: "...la totalitat de la filosofia s'assembla a una arbre, les arrels del qual són la metafisica, el tronc és la fisica, i les branques que broten 
d'aquest tronc són totes les altres ciéncies" (per a Descartes: la medicina, la mecànica i la moral: totes ciències pràctiques) (en Principis de la filosofia. "carta de l'autor al traductor"). Aquestes arrels metafisiques són per a Descartes "els principis del coneixement" que anomenem filosofia primera.

¿Pot embarcar Descartes en la nau de Neurath? Em quedaria satisfet si he pogut mostrar que la resposta no és tan senzilla com la tradició epistemològica ens diu: Descartes és el pare de l'arbre fonamentalista del coneixement.

Si adoptem la distinció quineana entre aspecte conceptual $\mathrm{i}$ aspecte doctrinal (veritatiu), en Descartes no hi ha empirisme conceptual, hi ha fonamentalisme metafisic que el trencaran per dues vies diferents Hume i Kant. I pel que fa a l'aspecte doctrinal ("justificar el nostre coneixement de les veritats de la natura en termes sensorials, val en Descartes per a la fisica aplicada, però no per a la física general (filosofia-metafisica-ontologia).

Presumiblement Descartes, com tots els filòsofs de la ciència en la modernitat, hauria de fer compatible navegar en la nau del coneixement cientific amb la vigilància del mateix des d'alguna aeronau epistemològica. Fer compatibles aquestes dues perspectives és des de Descartes. el sentit de l'epistemologia moderna. 